\title{
Flux modulated rotating pole piece magnetic gear
}

\author{
Mohd Firdaus M. A Halim ${ }^{1}$, E. Sulaiman' ${ }^{2}$, R. N. F. K. R. Othman ${ }^{3}$ \\ ${ }^{1,2}$ Research Center for Applied Electromagnetics, Faculty of Electrical and Electronic Engineering, Universiti Tun \\ Hussein Onn Malaysia (UTHM) Parit Raja, Johor Malaysia \\ ${ }^{1,3}$ Centre for Robotics \& Industrial Automation, Faculty of Electrical Engineering, Universiti Teknikal Malaysia Melaka
} (UTeM), Malaysia.

\begin{tabular}{|c|c|}
\hline Article Info & ABSTRACT \\
\hline Article history: & In this paper, the CMG is re-condition so that the pole piece act as the outer \\
\hline Received Mar 2, 2020 & $\begin{array}{l}\text { rotor instead of surface mount PM. This magnetic coupling of the CMG is } \\
\text { similar to the conventional CMG which uses harmonic to transfer the torque }\end{array}$ \\
\hline Revised May 1, 2020 & and speed from the inner rotor to the outer rotor. The working principle of \\
\hline Accepted Jun 26, 2020 & $\begin{array}{l}\text { the proposed CMG is derived analytically and simulated using finite element } \\
\text { software. For this recondition, the PM at the outer section become stationary }\end{array}$ \\
\hline Keywords: & $\begin{array}{l}\text { hence, retaining sleeve can be removing. The proposed MG produced } 18 \% \\
\text { higher average torque than the conventional MG with drawback in torque }\end{array}$ \\
\hline $\begin{array}{l}\text { Double rotor } \\
\text { Finite element }\end{array}$ & $\begin{array}{l}\text { ripple. The proposed CMG also produce higher gear ratio than the same pole } \\
\text { pair of conventional CMG. }\end{array}$ \\
\hline
\end{tabular}

Flux density harmonic

Flux switching

Magnetic gear

This is an open access article under the $\underline{C C B Y-S A}$ license.

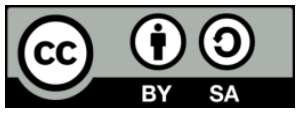

\section{Corresponding Author:}

Mohd Firdaus M. A Halim,

Research Center for Applied Electromagnetics, Faculty of Electrical and Electronic Engineering,

Universiti Tun Hussein Onn Malaysia (UTHM) Parit Raja,

Batu Pahat, Johor Malaysia

Email: mohd.firdaus@utem.edu.my

\section{INTRODUCTION}

The mileage of electric transportation is affected by the load range and the energy storage capacity. This factor is directly dominated by the total weight of the car and the propulsion's performance, reported by Larminie [1]. Thus, focus at the drive system must be examined. The components of the drive system are the electrical propulsion (electrical motor and transmission), the converter, and the energy storage. The energy flow within the system's components is two directions. The largest portion of losses is in the electrical propulsion, $72 \%$, on the static converter the loss is around 19\%, and at the battery level the loss is around $9 \%$ as shown in Figure 1. Hence, focusing mainly on the electrical propulsion by improving its efficiency and power density will improve the overall efficiency of the EV as published in several recent studies [2-4]. With regard to the existing propulsion solution, it can be seen that over time, the operating speed has substantially increased mentioned in numerous study [5-14]. All vehicle producers are competing at levelling up the velocity of vechile, acknowledging the enhancement of power density of the traction system, as well as EV's performance. In this relation, it must be reminded that higher speeds are not efficiently possible, since attached to the electric motor, a gear is placed in order to transfer the torque-speed to the car's traction wheels. Thus, in order to overcome this drawback, a research must be conducted. In this case, replacing mechanical gear to magnetic gear (MG) would serve as a preferable option.

Gears are used widely for speed and torque regulation in various field. It is common that the mechanical gear has a high torque to weight ratio, however, it suffers from losses in friction, noise, and heat, 
not to mention vibration and reliability issues. Differently, MG suggest significant edge of low maintenance const, reduced noise and vibration, reliable and protecting from overload. Moreover, in the past two decades, MGs have received relatively little interest, possibly due to its under par torque to weight and complexity mentioned in recent studies [15-17]. With the discovery of the high energy density neodymium iron boron (NdFeB) permanent magnet (PM) material in 1980s, the research on MGs incite new passion. In 2001, $\mathrm{K}$. Atallah designed a high torque density $\mathrm{MG}$ called as the coaxial magnetic gear (CMG), where it applies the principle of magnetic flux modulation between PM and pole piece [18, 19]. Based on the flux modulation technique, many CMG topologies were published [20-30]. CMG introduced by K. Atallah is reillustrated in Figure 2 in JMAG Application Note [31]. This magnetic gear has three important components, that is inner rotor, pole piece and outer rotor. The inner and outer rotor are mounted with permanent magnet which serve as the pole pair of the rotors.

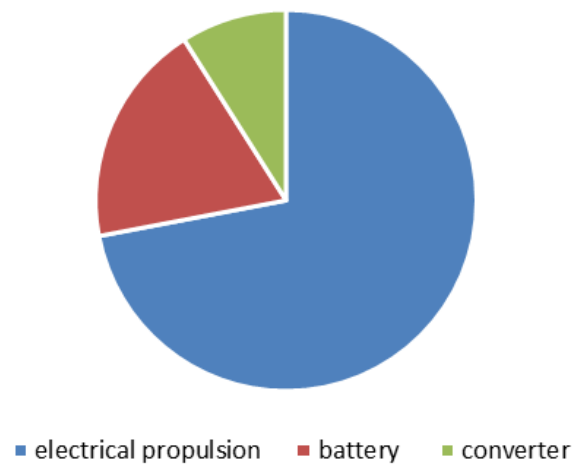

Figure 1. Losses in the drive chain component.

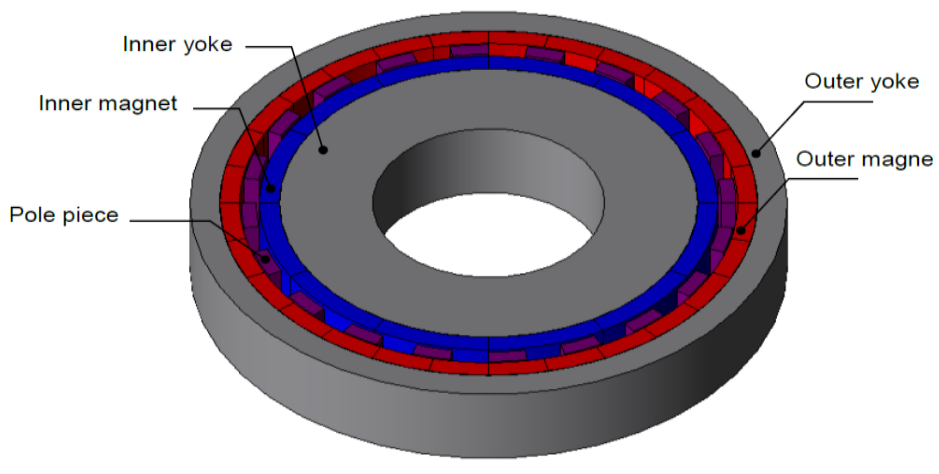

Figure 2. CMG structure.

Flux modulated type CMG consist of 2 rotors, inner and outer. Inner rotors is made of the PM pole pairs $\mathrm{p}_{\mathrm{h}}$ and yoke, outer rotor PM pole pairs $\mathrm{p}_{\mathrm{l}}$ with yoke and between the two rotos, there are ferromagnetic pole pieces $\mathrm{n}_{\mathrm{s}}$. From the inner rotor perspective, air gap magnetic flux density due to the inner rotor magnet is modulated by the pole piece, and harmonic occurs in the air gap. With the coupling of magnetic flux due to harmonic and outer rotor PM, torque is transferred. The relationship between $\mathrm{p}_{\mathrm{h}}, \mathrm{p}_{\mathrm{l}}$ and $\mathrm{n}_{\mathrm{s}}$ is shows in (1). The relationship between inner rotor speed $\mathrm{w}_{\mathrm{h}}$ and outer rotor speed $\mathrm{w}_{\mathrm{l}}$ when the pole piece is stationary is shown in (2).

$$
\begin{aligned}
& n_{s}=p_{h}+p_{l} \\
& w_{l} p_{l}=-w_{h} p_{h}
\end{aligned}
$$

CMG could achieve high torque density between $50-150 \mathrm{kNm} / \mathrm{m} 3$ comparable to the mechanical gear counterpart. However, it inherits the surface mount PM problem which are not robust similar to other surface mount PM machine reported in two papers [32, 33]. In the high-speed motor utilizing surfacemounted permanent magnet, the permanent magnets glue is insuffienct to sustain force acting towards outside of the motor, due to the high-speed motion of the rotor. In order to retain the permanent magnet on the rotor surface, a retaining sleeve is usually used placed around permanent magnet surface. The complexity of the design and manufacturability when retaining sleeve is employed may increase for a machine that use two surface mount rotor such as CMG.

In this paper, the CMG is re-condition so that the pole piece act as the outer rotor instead of surface mount PM. This magnetic coupling of the CMG is similar to the conventional CMG which uses harmonic to transfer the torque and speed from the inner rotor to the outer rotor. The working principle of the proposed CMG is derived analytically and simulated using finite element software. For this recondition, the PM at the outer section become stationary hence, retaining sleeve can be removed. The proposed CMG also produce higher gear ratio than the same pole pair of conventional CMG.

\section{WORKING PRINCIPLE}

When each term in equation (1) is multiplied with its own harmonic speed, it can be expressed as 


$$
w_{l} p_{l}+w_{h} p_{h}=w_{p} n_{p}
$$

Where $\mathrm{w}_{\mathrm{l}}, \mathrm{w}_{\mathrm{h}}$ and $\mathrm{w}_{\mathrm{p}}$ is the magnetic flux density harmonic speed of inner yoke surface mount PM, outer yoke surface mount PM and pole piece respectively.

In conventional CMG, wp is set to zero, hence arrived to (2). The gear ratio can be written as

$$
G_{r}=\frac{w_{h}}{w_{l}}=-\frac{p_{l}}{p_{h}}
$$

The negative sign means that the rotation direction between two rotors are in opposite direction. However, if $\mathrm{w}_{\mathrm{l}}$ is set to zero, the gear ratio can be written as (5)

$$
G_{r}=\frac{w_{h}}{w_{p}}=\frac{n_{p}}{p_{h}}
$$

The proposed CMG apply the condition of pole piece to be rotating while outer yoke surface PM condition is stationary. In this condition, the gear ratio is positive which indicates both rotating members are rotating in the same direction. The gear ratio when pole piece is in rotation is higher when outer yoke surface $\mathrm{PM}$ is in rotation, due to $\mathrm{n}_{\mathrm{p}}$ is the sum of $\mathrm{p}_{\mathrm{l}}$ and $\mathrm{p}_{\mathrm{h}}, \mathrm{n}_{\mathrm{p}}>\mathrm{p}_{\mathrm{l}}$. The objective of reducing the retaining sleeve is achieved now because the one of the surface mount PM now has became stationary. The magnetic field direction in the pole piece changes according to the harmonic frequency. The rotation of pole piece due to this effect can also be seen in flux-switching machine $[34,35]$.

\section{SIMULATION OF PROPOSED CMG}

\subsection{Geometry and setting}

The proposed CMG dimension and setting is shown in Table 1. The material used for inner yoke, stator yoke and pole piece are NSSMC $35 \mathrm{H} 210$ with resistivity of $5.9 \times 10-7 \Omega$, inner PM and outer PM, Hitachi NEOMAX 35AH at 1.2T residual, while plastic are placed between the pole piece to hold it together. Figure 3 shows the proposed CMG drawn using geometry editor of JMAG Designer version 16.

Table 1. Simulation dimension of proposed CMG

\begin{tabular}{lc}
\hline Parts & Proposed CMG \\
\hline Outer rotor & Pole piece \\
Outer pole pair $\left(\mathrm{p}_{\mathrm{l}}\right)$ & 14 \\
Pole piece $\left(\mathrm{n}_{\mathrm{p}}\right)$ & 20 \\
Inner pole pair $\left(\mathrm{p}_{\mathrm{h}}\right)$ & 6 \\
Gear ratio & $10 / 3$ \\
Inner rotor $\left(\mathrm{w}_{\mathrm{h}}\right)$ & $1000 \mathrm{rpm}$ \\
Outer rotor $\left(\mathrm{w}_{\mathrm{p}}\right)$ & $300 \mathrm{rpm}$ \\
MG radius & 90 \\
Inner pole pair radius & $68.5 \mathrm{~mm}$ \\
Shaft & $34 \mathrm{~mm}$ \\
Axial length & $30 \mathrm{~mm}$ \\
Inner magnet arc & $30^{\circ}$ \\
Pole piece arc & $9^{\circ}$ \\
Outer magnet arc & $12.857^{\circ}$ \\
Inner magnet width & $5 \mathrm{~mm}$ \\
Outer magnet width & $5 \mathrm{~mm}$ \\
Inner air gap width & $1 \mathrm{~mm}$ \\
Outer air gap width & $0.5 \mathrm{~mm}$ \\
\hline
\end{tabular}

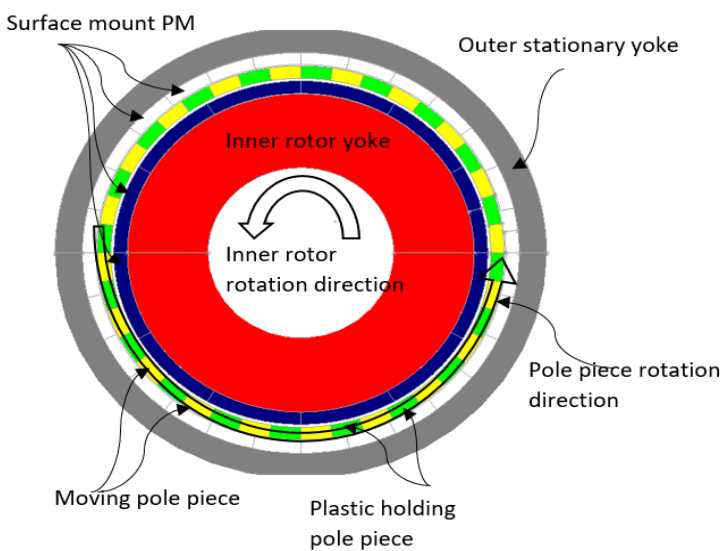

Figure 3. Proposed CMG structure

\subsection{Simulation result}

The torque waveform obtained when inner rotor and pole piece rotate at $1000 \mathrm{rpm}$ and $300 \mathrm{rpm}$ respectively is shown in Figure 4. Since the geometry is symmetrical, the simulation period is set $1 / 4$ of the full rotation. Table 2 summarized the result obtained from this simulation.

The negative torque simulated at the inner rotor indicates that an input torque is forced on the shaft of the inner rotor. Positive torque is produced at the pole piece implies that the output torque is generated and transferred from the action by the inner rotor magnetic field modulation. The torque ratio can be calculated through (6). 
$T_{r}=\frac{T_{p}}{T_{i}}=3.324 \sim 10 / 3=G_{r}$

Where $T_{r}$ is the torque ratio, $T_{p}$ is the torque at the pole piece and $T_{i}$ is the torque acting on the inner rotor. The average output torque at the pole piece is $18 \%$ larger than the equivalent conventional CMG (simulated separately). Torque density of the proposed $\mathrm{CMG}$ is equivalent to the conventional CMG. The only drawback observed was the torque ripple are quite large, over $30 \%$ more than the original CMG. Unlike the conventional CMG, pole piece and the plastic structure is assemble alternately. The magnetic field density is not continuously distributed as in surface mount PM; thus, torque ripple is expected to appear in the proposed CMG.

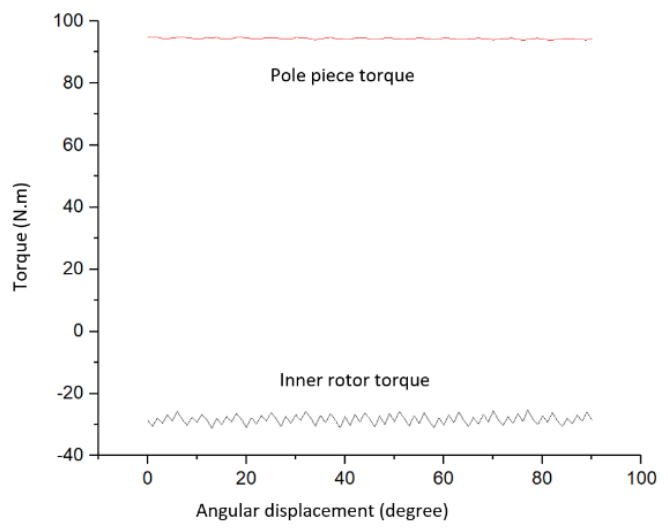

Table 2. Summary of result obtained from the simulation.

\begin{tabular}{lc}
\hline Parameters & Proposed CMG \\
\hline Inner rotor maximum torque (N.m) & $(-) 37.344$ \\
Outer rotor maximum torque (N.m) & 132.190 \\
Inner torque integral average (N.m) & $(-) 33.738$ \\
Outer torque integral average (N.m) & 112.245 \\
Inner torque ripple (\%) & 20.518 \\
Outer torque ripple $(\%)$ & 34.045 \\
Torque density $\left(\mathrm{T} / \mathrm{kN} . \mathrm{m} / \mathrm{m}^{3}\right)$ & 158.199 \\
\hline
\end{tabular}

Figure 4. Torque wavefor of the proposed CMG in $1 / 4$ rotatio

\section{CONCLUSION}

In this paper, new condition of coaxial magnetic gear is proposed that switch the output of the CMG from outer yoke surface mount PM to the pole piece. This condition enables the CMG designer to remove the retaining sleeve off the surface mount PM at the stationary stator. The working principle of the proposed CMG was explained and simulated with finite element. The proposed CMG can produce higher gear ratio compares to the conventional CMG. The result shows that the integral average torque is $18 \%$ higher than its equivalent conventional CMG. Nevertheless, torque ripple is quite large, over $30 \%$ than the conventional CMG. This limitation can be overcome through the introduction of auxiliary field coil which will be introduced in later publication.

\section{ACKNOWLEDGEMENTS}

The authors would like to thank the Ministry of Education Malaysia, Universiti Tun Hussein Onn Malaysia (UTHM) and Universiti Teknikal Malaysia Melaka (UTeM) for the technical and financial support of this research. This work was supported by the Research Management Centre, UTHM. [Research Fund E15501]. The authors also extend our gratitude to E. I Mbadiwe, S. M. N. S. Othman and L. I. Jusoh for their contributions to the preparation of the manuscript and research ideas.

\section{REFERENCES}

[1] J. Larminie and J. Lowry, Electric Vehicle Technology Explained: Second Edition, WILEY, 2012.

[2] D. Fodorean, F. Jurca, M. Ruba, and D. C. Popa, "Motorization Variants for Light Electric Vehicles. design, magnetic, mechanical and thermal aspects," in AlmaMater, 2013.

[3] J. De Santiago et al., "Electrical motor drivelines in commercial all-electric vehicles: A review," IEEE Trans. Veh. Technol., vol. 6, no. 2, pp. 475-484, 2012.

[4] I. Husain, "Electric and Hybrid Vehicles: Design Fundamentals, Second Edition," Amazon, 2010.

[5] D. Fodorean, "Study of a high-speed motorization with improved performances dedicated for an electric vehicle," IEEE Trans. Magn., vol. 50, no. 2, 2014.

[6] F. Luise et al., "Design and technology solutions for high-efficiency high-speed motors," in Proceedings - 2012 20th International Conference on Electrical Machines, ICEM 2012, 2012. 
[7] A. Tenconi, S. Vaschetto, and A. Vigliani, "Electrical machines for high-speed applications: Design considerations and tradeoffs," IEEE Trans. Ind. Electron., vol. 61, no. 6, pp. 3022-3029, 2014.

[8] G. Pellegrino, A. Vagati, B. Boazzo, and P. Guglielmi, "Comparison of induction and PM synchronous motor drives for EV application including design examples," IEEE Trans. Ind. Appl., vol. 48, no. 6, pp. 2322-2332, 2012.

[9] D. Gerada, A. Mebarki, N. L. Brown, K. J. Bradley, and C. Gerada, "Design aspects of high-speed high-powerdensity laminated-rotor induction machines," IEEE Trans. Ind. Electron., vol. 58, no. 9, pp. 4039-4047, 2011.

[10] S. Il Kim, Y. K. Kim, G. H. Lee, and J. P. Hong, "A novel rotor configuration and experimental verification of interior pm synchronous motor for high-speed applications," in IEEE Transactions on Magnetics, vol. 48, no. 2, pp. 843-846, 2012.

[11] D. P. Marčetić, I. R. Krčmar, M. A. Gecić, and P. R. Matić, "Discrete rotor flux and speed estimators for highspeed shaft-sensorless im Drives," IEEE Trans. Ind. Electron., vol. 61, no. 6, pp. 3099-3108, 2014.

[12] R. R. Moghaddam, F. Magnussen, and C. Sadarangani, "Theoretical and experimental reevaluation of synchronous reluctance machine," IEEE Trans. Ind. Electron., vol. 57, no. 1, pp. 6-13, 2010.

[13] J. H. Seo, T. K. Chung, C. G. Lee, S. Y. Jung, and H. K. Jung, "Harmonic iron loss analysis of electrical machines for high-speed operation considering driving condition," in IEEE Transactions on Magnetics, vol. 45, no. 10, pp. 4656-4659, 2009.

[14] D. Fodorean, "State of the Art of Magnetic Gears, their Design, and Characteristics with Respect to EV Application," in Modeling and Simulation for Electric Vehicle Applications, Mohamed Amine Fakhfakh, IntechOpen, 2016.

[15] D. E. Hesmondhalgh and D. Tipping, "A multielement magnetic gear," IEE Proc. B Electr. Power Appl., vol. 127, no. 23, pp. 129-138, 1980.

[16] K. Tsurumoto and S. Kikuchi, “A new magnetic gear using permanent magnet,” IEEE Trans. Magn., vol. 23, no. 5, pp. 3622-3624 1987.

[17] C. G. C. Neves, D. L. Figueiredo, and A. S. Nunes, "Magnetic Gear: A Review," 2014 11th IEEE/IAS Int. Conf. Ind. Appl., pp. 1-6, 2014.

[18] K. A. and D. Howe, "A novel high-performance linear magnetic gear," IEEE Trans. Magn., vol. 37, no. 4, pp. 2844-2846, 2001.

[19] S. D. C. and D. H. K. Atallah, "Design, analysis and realisation of a high- performance magnetic gear," IEE Proceedings-Electric Power Appl., vol. 150, no. 2, pp. 139-145, 2004.

[20] X. Li, K. T. Chau, M. Cheng, and W. Hua, "Comparison of magnetic-geared permanent-magnet machines," Prog. Electromagn. Res., vol. 133, no. Aug 2013, pp. 177-198, 2013.

[21] X. Zhang, X. Liu, C. Wang, and Z. Chen, "Analysis and Design Optimization of a Coaxial Surface-Mounted Permanent-Magnet Magnetic Gear,” Energies, vol. 7, no. 12, pp. 8535-8553, 2014.

[22] C. S. Gim, E. J. Park, S. Y. Jung, and Y. J. Kim, "Torque Characteristic Analysis of Coaxial Magnetic Gear According to Fillet Parameter of Pole Piece," ICEMS 2018 - 2018 21st Int. Conf. Electr. Mach. Syst., no. 1, pp. 2557-2560, 2018.

[23] Xianglin Li, K. T. Chau, M. Cheng, W. Hua and Y. Du, "A new coaxial magnetic gear using stationary permanent magnet ring," 2013 International Conference on Electrical Machines and Systems (ICEMS), Busan, pp. 634-638, 2013.

[24] J. X. Shen, H. Y. Li, H. Hao, M. J. Jin, and Y. C. Wang, "Topologies and performance study of a variety of coaxial magnetic gears," IET Electr. Power Appl., vol. 11, no. 7, pp. 1160-1168, 2017.

[25] K. Aiso, K. Akatsu, and Y. Aoyama, "Reluctance magnetic gear and flux switching magnetic gear for high speed motor system," 2017 IEEE Energy Convers. Congr. Expo. ECCE 2017, pp. 2445-2452, 2017.

[26] E. Park, C. Gim, S. Jung, and Y. Kim, "A gear efficiency improvement in magnetic gear by eddy-current loss reduction," Int. J. Appl. Electromagn. Mech., vol. 1, pp. 1-10, 2018.

[27] B. McGilton, R. Crozier, and M. Mueller, "Optimisation procedure for designing a magnetic gear," J. Eng., vol. 2017, no. 13, pp. 840-843, 2017.

[28] C. C. Huang, M. C. Tsai, D. G. Dorrell, and B. J. Lin, "Development of a magnetic planetary gearbox," IEEE Trans. Magn., vol. 44, no. 3, pp. 403-412, 2008.

[29] J. L. Perez-Diaz, E. Diez-Jimenez, M. A. Alvarez-Valenzuela, J. Sanchez-García-Casarrubios, C. Cristache, and I. Valiente-Blanco, "Magnetic Gearboxes for Aerospace Applications," Aerosp. Mech. Symp., pp. 365-374, 2014.

[30] S. Kim, E. Park, and Y. Kim, "Optimal Design of Ferromagnetic Pole Pieces for Transmission Torque Ripple Reduction in a Magnetic-Geared Machine," J. Electr. Eng. Technol., vol. 11, no. 6, pp. 1628-1633, 2016.

[31] J. Corporation, “JMAG Application Note 207," pp. 1-16, 2015.

[32] J. Dong, Y. Huang, L. Jin, and H. Lin, "Comparative Study of Surface-Mounted and Interior Permanent-Magnet Motors for High-Speed Applications," IEEE Trans. Appl. Supercond., vol. 26, no. 4, pp. 26-29, 2016.

[33] L. Chen and C. Zhu, "Strength Analysis for Surface-mounted Permanent Magnet Rotor in High-Speed Motor," TELKOMNIKA Indones. J. Electr. Eng., vol. 12, no. 10, 2014.

[34] E. I. Mbadiwe and E. Sulaiman, "Improved design of outer rotor machine in PM technology for motor bike drive application," in ISCAIE 2018-2018 IEEE Symposium on Computer Applications and Industrial Electronics, 2018.

[35] M. F. Omar, E. Sulaiman, H. A. Soomro, F. Amin, L. I. Jusoh, and E. I. Mbadiwe, "Optimal design of single-phase 12S-6P FEFSM using segmental rotor and non-overlap windings," Indones. J. Electr. Eng. Comput. Sci., vol. 14, no. 2, pp. 735-743, 2019. 


\section{BIOGRAPHIES OF AUTHORS}
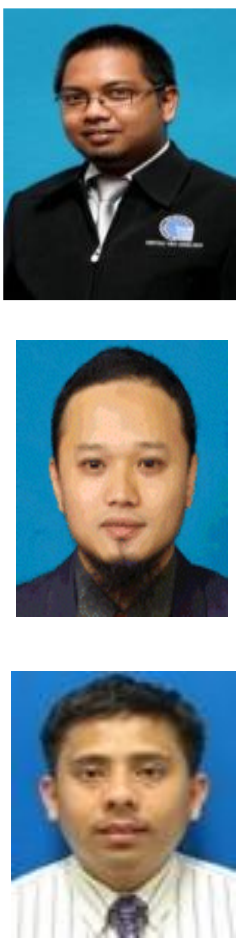

Mohd Firdaus Mohd Ab Halim is a researcher and engineer. He graduated from Universiti Tenaga Nasional in Bachelor of Electrical Engineering. He finished Master Degree of EEIT at University of Applied Science Rosenheim, Germany. He worked in various multinational company such as Sony Intel and Qimonda as Electrical Test Engineer. Currently he is a full-time researcher at Universiti Teknikal Malaysia Melaka, Fakulti Teknologi Kejuruteraan. His reseach mainly focus in Energy Efficiency, Renewable Energy and Electrical Vehicle. Currently he is full time studying Doctor Of Philosophy In Electrical Engineering in Universiti Tun Hussein Onn (UTHM)

Erwan bin Sulaiman received his B.E and M.E degrees in Electrical Engineering from University of Malaya in 2001 and University Tun Hussein Onn Malaysia (UTHM) in 2004. He has been with UTHM from December 2004 as a lecturer. He received Doctor Degree in Electrical Engineering from Nagoya Institute of Technology (NIT), Japan in 2012. He is currently Associate Professor at Department of Electrical Power Engineering, University Tun Hussein Onn Malaysia. His research interests include design optimizations of HEFSM, WFFSM, in particular, for HEV drive applications.

Raja Nor Firdaus Kashfi Raja Othman received his B. Eng in Electrical \& Electronics,

M.Sc in Electrical Machine Design \& Applied Magnetics and PhD in Electrical Machine and Design from Universiti Putra Malaysia. He is an Associate Professor of Department of Power Electronics and Drives, Faculty of Electrical Engineering (FKE). He is currently the manager Center for Robotic and Industrial Automation. He specialized in Electric Machines Design, Magnetic Sensor, Power Electronics \& Drives 